\title{
Measuring lung motion for better lung cancer treatment
}

\section{Maida Ranjbar \\ Pouya Sabouri \\ Carlo Repetto \\ Amit Sawant}

\section{Video Byte}

Keywords: lung, lung motion, lung phantom, lung motion phantom, lung cancer, lung tumor, cancer, tumor, breathing, respiratory system, repiratory motion management, respiratory cycle, radiotherapy, radiation therapy, cancer radiotherapy, medicine, radiation oncology, Ranjbar, University of Maryland, University of Maryland School of Medicine

Posted Date: September 20th, 2019

DOI: https://doi.org/10.21203/rs.2.15132/v1

License: (9) This work is licensed under a Creative Commons Attribution 4.0 International License. Read Full License 


\section{Abstract}

Lung phantoms are dynamic systems that simulate lung motion to predict tumor position for lung radiotherapy These predictions make cancer radiotherapy more precise, as lung tumors move during breathing Unfortunately, current lung motion phantoms don't account for complex motion and deformation of surrounding organs Now, researchers at the University of Maryland, Baltimore, have developed a lung phantom that can produce complex and irregular motions by using a motion platform with two independently programmable linear actuators The phantom provides reliable measurements of the tumor as well as surrounding organs at risk and can simulate variation in abdominal and thoracic engagement While the new lung phantom can't fully reproduce human breathing, it comes pretty close It is a valuable tool for evaluating motion management strategies in lung radiotherapy Ranjbar et al. "A novel deformable lung phantom with programably variable external and internal correlation." Medical Physics (2019) 